\title{
El patrimonio bibliográfico comunitario de Santa María de la Vega (Salamanca) en 1577
}

\section{Ana SUÁREZ GONZÁLEZ}

Universidad de Santiago de Compostela

Santa María de la Vega, estramuros de la noble çibdad de Salamanca $^{1}$, fue residencia de los canónigos regulares de San Isidoro de León que acudían a completar su formación en la universidad salmantina. Convertida en filiación isidoriana ya en 1166, ignoramos cuándo comenzó la casa de La Vega a recibir estudiantes procedentes de la Real Colegiata leonesa porque la información al respecto es parca hasta el siglo XVI. La decimosexta centuria se muestra, sin embargo, especialmente rica en noticias acerca del priorato -uno de los principales 'colegios religiosos' ${ }^{2}$ salmantinos- y, por ello, es el periodo en el cual podemos adentrarnos en su recinto, abrir su biblioteca y conocer a los usuarios de los libros.

Iniciamos la visita el 2 de junio de 1577, Domingo de la Trinidad, acompañando al muy Magnífico y muy Reuerendo señor Joan de Villafañe, prior de San Isidoro de León y encargado de inspeccionar la casa salmantina por mandato del abad Zúñiga y Avellaneda ${ }^{3}$.

\section{1.- Los usuarios.}

Cuando Santa María de la Vega se incorporó a San Isidoro de León -por donación de Velasco Ennego, su esposa -Amadona-, su hermana -Iusta- y otros parientes ${ }^{4}$ - se estableció que, en adelante, de-

\footnotetext{
${ }^{1}$ ASIL, Documentación en papel, L/101-4.

${ }^{2}$ Cf. J. ALEJO MONTES, La Universidad de Salamanca bajo Felipe II (15751598), Burgos 1998, p.292.

3 "Visita de Nuestra Señora de la Vega, extramuros de la ciudad de Salamanca, filiaçión del monasterio de Sancto Isidro el Real de la çiudad de León, de canónigos reglares de la orden de Sant Augustín, la qual hizo el muy Magnífico y muy Reuerendo señor Joan de Villafañe, prior en el dicho monasterio, por comisión del muy illustre y rreberendísimo señor Don Pedro de Çúñiga y Auellaneda, abbad perpetuo del dicho monasterio. Començóse Domingo, día de la Trinidad, que se contaron 2 de junio del anno de 1577" (ASIL, Documentación en papel, L/102-1, f.[1]r). Se menciona ya la gestión de esta visita en reunión capitular del 29 de mayo de 1577 (ASIL, Documentación en papel, I-e/74-1,b, f.110r).

${ }^{4}$ Velasco Ennego, junto su esposa -Amadona-, su hermana -Iusta- y otros parientes, entregan esta propiedad al abad Menendo y los canónigos isidorianos, bajo ciertas condiciones En 1166, abril, 6 (ASIL 308). Custodia el archivo isidoriano un documento fechado en 1163 en el cual el mismo benefactor y su esposa donaban a los monjes que en él vivían el monasterio de Santa María de la Vega (ASIL 303). Sobre
} 
Ana Suárez

bería residir en el monasterio una comunidad no inferior a siete miembros. Esta condición se ratifica en las Decisiones presentadas en 18 de diciembre de 1555 por el visitador y reformador Martín de Azpilcueta ("el doctor navarro") 5 . Siete era, pues, el número mínimo, pero no el más adecuado en opinión del cabildo isidoriano: la experiencia demostraba cómo en el siglo XVI resultaba aconsejable un mínimo de diez 'moradores', ya que, en caso contrario, no podía dexar de padecerse defectos assí en el culto diuino como el estudio y exerçiçio de las escuelas ${ }^{6}$.

Además, convenía que se enviasen a la Vega algunos moradores que no fuesen para studiar, sino saçerdotes para assistir en casa con el señor vicario, que hasta aquí, como se iban los studiantes a su offiçio, quedaba los más días solo en casa ${ }^{7}$.

La comunidad residente en la casa salmantina se compone, por tanto, de sacerdotes y estudiantes encabezados por un prior, llamado comúnmente vicario, que nombra el cabildo isidoriano ${ }^{8}$. Los estudiantes son miembros de la canónica leonesa que acuden a 'las escuelas' de Salamanca a completar su formación académica en Derecho canónico y Teología 9 . Las conversaciones -y posteriores resolucionesde los capitulares isidorianos muestran que realizar estudios superiores en la Universidad es, en cierto modo, un privilegio y, por ello, decidir quién puede beneficiarse de esta gracia no es un asunto banal, requiere una adecuada valoración de los candidatos ${ }^{10}$. Las actas capitulares evidencian que los destinados a la Vega para estudiar deben cumplir dos requisitos: juventud y aptitudes para el aprendizaje. Sin embargo,

Santa María de la Vega -fundación, evolución, características- y su relación con la comunidad de San Isidoro de León, véase A. SUÁREZ GONZÁLEZ, La formación en San Isidoro de León entre 1167 y 1579: cuatro siglos de maestros y estudiantes: Volumen conmemorativo del XXV aniversario de la Universidad de León, León 2004 [en prensa].

${ }^{5}$ El 18 de diciembre de 1555 (ASIL, Documentación en papel, I-b/70-1): Martinus ab Azpilcueta, vulgo Doctor Nauarro: "Declaramus juris esse vt hoc illustre S. Isidori monasterium mittat in praefactam ecclesiam Beatae Mariae de Valle quo in ea morentur, et Deum de more collant saltem septem canonicos Sancti Augustini in hoc monasterio professos" (...).

${ }^{6}$ En 1556, junio, 5 (ASIL, Documentación en papel, I-e/74-1,a, f.48r).

${ }^{7}$ En 1579, mayo, 15 (ASIL, Documentación en papel, I-e/74-1,b, f.153v).

${ }^{8}$ Conocemos los nombres de algunos de los siglos XIV y XV y la totalidad de los que ejercieron este cargo desde el primer tercio del siglo XVI (cf. A. SUÁREZ GONZÁLEZ, La formación).

${ }^{9}$ Cf. A. SUÁREZ GONZÁLEZ, La formación.

${ }^{10}$ En las Decisiones de 1555 (controversia decimocuarta) debidas a Azpilcueta se hace también referencia explícita a esta cuestión (cf. ASIL, Documentación en papel, I-b/70-1). 
las reuniones del cabildo ponen de manifiesto cómo otros factores pueden interferir en la designación de estudiantes: unas veces no conviene enviar moradores a Nuestra Señora de la Vega porque la filiación atraviesa un mal momento económico y otras se suspenden los traslados porque la canónica isidoriana es pobre en vocaciones.

Ambos condicionantes extra-académicos se conjugaron en torno a 1577 y, debido a ello, cuando el prior isidoriano Juan de Villafañe llega a Nuestra Señora de la Vega la comunidad se halla bajo mínimos. Sólo son seis los "moradores"11.

Mitad monasterio, mitad Colegio mayor, no es raro que esta reducida comunidad aúne presbíteros y diáconos, canónigos con grado universitario y estudiantes. El miembro con más alto título académico es Cristóbal de Toro, elegido prelado de La Vega el 30 de diciembre de $1573^{12}$, y que, en el momento de la visita, era vicario "en funciones ${ }^{13}$, puesto que su trienio se cumplió y acabó a diez y ocho de março próximo passado.

Su sucesor en el cargo será el canónigo Pedro Zapata, bachiller, nombrado un mes después de la visita ${ }^{14}$ y el regreso de Toro a la Colegiata leonesa se ordena en reunión capitular celebrada el 26 de julio, advirtiendo que procurase traer algún dinero cuando se viniesse $e^{15}$.

Cristóbal de Toro aparece mencionado en la visita como licenciado $^{16}$. De su excelencia intelectual tenemos ya noticia en 1566,

${ }^{11}$ ASIL, Documentación en papel, L/102-1, f.[3]v. La situación era mejor en años anteriores. En 28 de marzo de 1531 conformaban la comunidad Lope Hernández, vicario, el bachiller Diego Flórez, el bachiller Cristóbal de Robles, el bachiller Fernando Martín, el bachiller Francisco de Marquina, Alonso de Abastas, Pedro de Reynoso y Gutierre de Quirós "todos canónigos profesos" (ASIL, Documentación en papel, L/101-4). En noviembre de 1574 la componían el vicario Cristóbal de Toro, Antonio de Sepúlveda, Pedro Zapata, Diego de Vega, Lázaro de Quiñones, Hernando de Rojas y Cristóbal de Sacrameña (ASIL, Documentación en papel, I-e/74-1,b, f.17v).

${ }^{12}$ Es elegido vicario de la Vega en la reunión del cabildo isidoriano que tuvo lugar dicho día. Toro obtuvo nueve votos (ASIL, Documentación en papel, I-e/74-1,a, f.305r).

${ }^{13}$ Falleció un 6 de junio: “... Famuli Dei licentiati Toro, vicarii Sancte Mariae de la Vega" (ASIL, Códice LXXV). la documentación relativa a la almoneda de sus bienes se fecha en julio y agosto de 1591 (ASIL, Documentación en papel, F-b/ 44, 39). $1, \mathrm{~b}, \mathrm{f} .112 \mathrm{v})$

${ }^{14}$ Nombrado el 12 de julio de 1577 (ASIL, Documentación en papel, I-e/74-

${ }_{16}^{15}$ ASIL, Documentación en papel, I-e/74-1,b, ff.112v-113r.

${ }^{16}$ ASIL, Documentación en papel, L/102-1, f. [3]r. 
Ana Suárez

cuando opositó al cabildo isidoriano y los capitulares se refieren a él elogiosamente, calificándolo de muy buen letrado theólogo ${ }^{17}$.

Junto al licenciado Toro, residen en la Vega cuatro presbíteros más y un diácono. Son presbíteros Diego de Vega Lorenzana, Francisco de Huerga, Lázaro de Quiñones y Hernando de Rojas; el diácono o ‘evangelistero' es Tristán de Pernía ${ }^{18}$.

El bachiller Diego de Vega Lorenzana ${ }^{19}$, que desempeñaba en 1577 el cargo de secretario, 'moraba' desde hacía varios años en Salamanca. Su destino a La Vega es consecuencia de un acuerdo del cabildo isidoriano fechado en 4 de agosto de 1571, decisión que responde a razones excepcionales Vega, infante, sabía poco y en esta casa no podía deprender por no aver lugar para estudiar y el trabajo del coro era mucho. Y sus deüdos deseaban que fuesse a Salamanca y le pagarían vn maestro que le enseñase gramática en casa y no saliesse fuera a oirla, por ser afrenta desta casa, y lo pagarían a su costa porque supiesse algo y se aprovechache $(\mathrm{sic})^{20}$.

El estudiante avanzó lo suficiente como para acceder a estudios universitarios. En la reunión de los capitulares isidorianos que tuvo lugar el 20 de junio de 1572 se expone que Diego de Vega, infante, estaba en Nuestra Señora de la Vega de Salamanca estudiando gramática en casa y tenía cédula para pasar a otra facultad. Y pedía al capítulo se señallasen (sic) qué facultad querían que oyese. Determinóse oyese Artes, de San Lucas adelante ${ }^{21}$, deste año $72^{22}$.

${ }^{17}$ En 1566, julio, 8 (ASIL, Documentación en papel, I-e/74-1,a, f.186v). En reunión del cabildo celebrada el sábado 21 de abril de 1586 fue elegido prior de la Real Colegiata (ASIL, Documentación en papel, I-e/74-1,b, f.265r).

${ }_{18}^{18}$ ASIL, Documentación en papel, L/102-1.

${ }^{19}$ Aparece documentado con este título en 1579 (ASIL, Documentación en papel, I-b / 70-2, f.2r).

${ }^{20}$ ASIL, Documentación en papel, I-e/74-1,a, f.258v. El cabildo le concede licencia para "que cante misa" el 7 de octubre de 1575 (ASIL, Documentación en papel, I-e/74-1,b, f.53r).

${ }^{21}$ En la Universidad de Salamanca "El curso académico comenzaba el 18 de octubre, día de San Lucas, y terminaba el 8 de septiembre, festividad de Nuestra Señora de Septiembre, quedando un mes y diez días de vacaciones" (J. ALEJO MONTES, La Universidad de Salamanca bajo Felipe II (1575-1598), Burgos 1998, p.235). "Originariamente el curso escolar se extendía a lo largo de todo el año (...) poco a poco se fue extendiendo en el mundo universitario de influencia boloñesa el inicio el día el 18 de octubre, festividad de san Lucas" (S. CLARAMUNT RODRÍGUEZ, La transmisión del saber en las universidades: La enseñanza en la Edad Media, Logroño 2000, p.147).

...y también cumplía su edad, que le diesen reberendas para ordenarse de epístola, determinóse que se las imbíen (ASIL, Documentación en papel, I-e/74-1,a, f.277r). 
Poco después de la visita lo hallamos ya como huésped en la Real Colegiata leonesa, casa en la que pasó a residir a partir de agosto del mismo año ${ }^{23}$.

Por lo que se refiere a Hernando de Rojas, se encontraba la filial salmantina desde 1572. El 25 de febrero de dicho año los canónigos isidorianos deciden su traslado a La Vega por morador y estudiante, porque se aprovechase agora, antes que entrase en más $e d a d^{24}, \mathrm{y}$ acuerdan su regreso a León en reunión celebrada el 15 de mayo de 1579 por haber ya acabado de oír en Salamanca ${ }^{25}$.

En mayo de 1573 el cabildo determina que Lázaro de Quiñones vaya a La Vega por morador y estudiante" 26 .

Sin embargo, en reunión celebrada un mes después, deciden los capitulares que resida en este convento desde aquí a Sanct Lucas, atento la neçessidad que ay, y entonçes se le dirá los días en que ha de compadescer en Salamanca y ser morador en la dicha casa de la $\operatorname{Vega}^{27}$.

Este presbítero permanecerá en Salamanca hasta 1578. El 28 de noviembre de dicho año los canónigos isidorianos acuerdan que 'more' nuevamente en la Colegiata, donde residía ya como huésped ${ }^{28}$.

Francisco de Huerga, tesorero de la comunidad en el momento de la visita, y Tristán de Pernía habían sido nombrados "por moradores de la Vega" un año antes de la visita, el 11 de mayo de $1576^{29}$. Sabemos, a partir de la reunión del cabildo isidoriano celebrada el 15 de septiembre de 1582, que el primero de los citados aún no había concluido sus estudios en Salamanca y que al segundo por sus indispu-

${ }^{23}$ Por ser pocos entonces los canónigos isidorianos (1577, agosto, 1, ASIL, Documentación en papel, I-e/74-1,b, f.113v). El canónigo Diego de Vega Lorenzana murió en esta santa casa, jubilado, año de 623 y fue prior de ella (ASIL, Códice XCIII, f.22v).

${ }^{24}$ ASIL, Documentación en papel, I-e/74-1,a, f.271r. Se le concede licencia para "órdenes de misa" el 10 de diciembre de 1574 (ASIL, Documentación en papel, Ie/74-1,b, f.19v).

${ }^{25}$ ASIL, Documentación en papel, I-e/74-1,b, f.153v. Falleció el canónigo "cura y procurador de Nuestra Señora de Montesión del lugar de Herrín" el 25 de noviembre de 1584 (ASIL, Códice XCIII, f.21v).

${ }^{26}$ ASIL, Documentación en papel, I-e/74-1,a, f.293r,

${ }^{27}$ ASIL, Documentación en papel, I-e/74-1,a, f.294v.

${ }^{28}$ ASIL, Documentación en papel, I-e/74-1,b, f.144r. En 1587 solicita volver a la Vega (ASIL, Documentación en papel, I-e/74-1,b, f.289r).

${ }_{29}$ ASIL, Documentación en papel, I-e/74-1,b, f.80r. 
Ana Suárez

siçiones se le podía perdonar el pasar adelante en su estudio ${ }^{30}$, hecho que justifica su retorno a León a partir del 1 de mayo de $1583^{31}$. El regreso a San Isidoro de Francisco de Huerga no se acuerda hasta $1585^{32}$.

\section{2.- Los libros.}

La casa de Nuestra Señora de la Vega está muy presente en la vida cotidiana de San Isidoro. Intermitentemente aparece en las reuniones del cabildo a través de la correspondencia que el vicario y otros 'moradores' en Salamanca mantienen con los capitulares leoneses. El contenido de estas misivas, las correspondientes respuestas de los miembros de la canónica isidoriana, las decisiones sobre el envío o el regreso de moradores de la filial salmantina, etc. dejan muy claro que dos son las obligaciones de la pequeña comunidad de la Vega: la atención al "culto divino" y el "estudio y ejercicio de las escuelas" 33 , o, dicho de otro modo, la actividad cultual-litúrgica, por su condición de regulares, y la formación académica universitaria reservada a los estudiantes. No es extraño, pues, que los libros, en tanto instrumentos, respondan a estas finalidades y podamos establecer en el conjunto bibliográfico comunitario dos grupos: uno que comprende los ejemplares destinados a la liturgia -eucaristía y Oficio divino- y otro constituido por los volúmenes relacionados de alguna manera con la formación, tanto la edificación espiritual como la instrucción académica.

Además, la visita a la casa salmantina en 1577 evidencia cómo, al igual que sucedía en otros centros eclesiásticos desde la Edad Media, las distintas funciones y el uso de los libros se relacionan estrechamente con diferentes espacios destinados a su custodia. En Santa María de la Vega la mayoría de los ejemplares litúrgicos se hallan depositados en dos lugares -el coro y la sacristía- y los restantes se ubican en la denominada librería que compartía habitáculo con el tesoro.

Son probablemente estos últimos, los ejemplares de la librería, los destinados a la formación, a los que el cabildo isidoriano debía prestar mayor atención, aun cuando su adquisición supusiera un im-

\footnotetext{
${ }^{30}$ Se propone su regreso a León junto a otros dos moradores, pero el cabildo no desea que "perdiesen el estudio los que le auían enpezado" y, por ello, se desestima la vuelta de Huerga (ASIL, Documentación en papel, I-e/74-1,b, f.213r).

${ }^{31}$ En la reunión capitular de dicho día se acuerda su vuelta a la Colegiata (ASIL, Documentación en papel, I-e/74-1,b, f.226r).

${ }^{32}$ ASIL, Documentación en papel, I-e/74-1,b, f.251. "Don Francisco de Guerga, prior que fue desta santa casa y de San Andrés de Villalpando, adonde murió el año de 610" (ASIL, Códice XCIII, f.22r).

${ }^{33}$ En 1556, junio, 5 (ASIL, Documentación en papel, I-e/74-1,a, f.48r).
} 
portante desembolso. Uno de los apuntes insertos en la documentación de la visita se refiere a tres volúmenes que contienen la glossa ordinaria y tratados de san Ambrosio. La observación del secretario a propósito de estos ejemplares tiene gran interés: se compraron de la dézima que cabía a los illustres señores prior y conbento de Santo Isidro de León, de la qual parte hizieron merced a esta casa para comprar libros por ser casa de studio ${ }^{34}$.

Esta nota nos recuerda una importante decisión de los capitulares isidorianos resultado de la reunión celebrada el 12 de octubre de 1571, cuando perdonó el convento su parte de la décima a Nuestra Señora de la Vega de Salamanca". La determinación responde a una petición del vicario de La Vega ${ }^{35}$ : Leyóse una carta del vicario de Nuestra Señora de la Vega, entre otras, que daba cuenta de aquella casa deste monasterio. Se le abía perdido (sic) vnbiasse (sic) vna tazmía de lo que abía balido la rrenta de aquel monasterio y que tanto abía que este monasterio le abía hecho graçia de la parte que le cabe de la déçima. Y el dicho vicario suplicaba a este conbento fuessen servidos se atribuesse [a] aquella casa para obras y otras cosas, por tener harta neçessidad y estar por el suelo y tener gran falta de aposentos para religiosos y otros edificios necessarios. Determinóse por todo el capítulo que, pues el señor abbad don Pedro de Acuña abía perdonado la déçima, que también este convento la perdonava por tener más rraçones para ello y desde ahora lo aplicaua para vna librería, pues avía gran falta en ella y era tan neçessaria en vna casa como aquella de estudiantes. Y el vicario que era de presente dava sus libros, otros harían otro y todos nos criadmos (sic) y deprendemos en ella ${ }^{36}$.

Pese a esta generosa renuncia en favor de los libros, la relación de ejemplares que custodia la librería salmantina seis años después parece excesivamente breve si la comparamos con los repertorios de otras bibliotecas eclesiásticas coetáneas. Tal vez porque la visitamos cuando acaba de ser expurgada y desprovista de los ejemplares tenidos en el momento por no ortodoxos, quizá porque los 'moradores' de la Vega contaban con suficientes libros de propiedad y uso privado para su formación ${ }^{37}$.

${ }^{34}$ ASIL, Documentación en papel, L/102-1, f.[23]r.

${ }^{35} \mathrm{El}$ texto presenta varios errores que atribuimos a una copia al dictado: perdido por pedido, vn biasse por enviasse, etc.

${ }^{36}$ ASIL, Documentación en papel, I-e/74-1, a, ff. 262v-263r.

${ }^{37}$ Sabemos que en la época que nos ocupa canónigos residentes en la Vega y en la Colegiata leonesa disponían de colecciones de libros. Podemos citar algunos ejemplos. Conocemos la rica biblioteca del bachiller Francisco Fernández, inventariada en Nuestra Señora de la Vega de Salamanca en marzo de 1531, tras su fallecimiento 
Ana Suárez

\subsection{Libros de sacristía.}

Dedicada a la guarda de los objetos litúrgicos vinculados al desarrollo de la misa, cobija la sacristía los libros destinados al mismo cometido. No es raro, por tanto, que todos los ejemplares en ella depositados, un total de veintidós, sean misales. De ellos, sin embargo, sólo resultan útiles tres, del reço nuebo, el vno grande, los otros dos pequeños (el vno más que el otro). Los restantes diez y nuebe missales, biejos, del reço antiguo ya no siruen. Evidente, pues, la escasez de ejemplares, el prior isidoriano ordena la adquisición de varios misales nuevos: Mandó el dicho señor prior se comprasen otros tres missales de los nuebos para que aya en todos seis <mandato: no III sino quatro $>38$

Del aspecto externo de los misales apenas sabemos nada a partir de la documentación que genera la visita, sólo contamos con una referencia escueta e imprecisa al tamaño de los tres ajustados al 'rezo nuevo'. Tampoco se llevan a cabo precisiones sobre el contenido, tal vez porque en todos los casos se trataba de misales plenarios que comprenderían, además, el ciclo litúrgico completo.

\subsection{Libros de coro.}

También con fines litúrgicos, dispone la comunidad de la Vega de una biblioteca coral en la que dominan los volúmenes que comúnmente se conocen como cantorales, por reunir las piezas entonadas o cantadas en el desarrollo del Oficio divino y de la misa.

$\mathrm{Si}$ atendemos a los apuntes de la visita, son trece los volúmenes que se hallan en el coro. El primero de los citados -que suponemos

(1531, marzo, 28, cf. ASIL, Documentación en papel, L/101-4), biblioteca que estamos estudiando actualmente. El 26 de abril de 1577 el capítulo a pedimiento del dicho liçençiado Sanctollano determinó se le bendiesen algunos libros que ay en la librería doblados y sin ningún prouecho. El qual negoçio -para que viesen los que se podían vender y los que no- se cometió a los canónigos Antonio Ortiz y Juan García (ASIL, Documentación en papel, I-e/74-1,b, f.108r). En una reunión del cabildo isidoriano celebrada el 2 de julio de 1577 se acuerda el envío a Salamanca de los "libros de astrología" del fallecido canónigo Santa Cruz de Villafañe para que se proceda allí a su venta (ASIL, Documentación en papel, I-e/74-1,b, f.111v) y el 26 de julio del mismo año, cuando se decide el regreso a León del licenciado Toro, se recuerda que debe traer a la Colegiata el dinero que monta los libros y instrumentos de astrología de Santa Cruz de Villafañe que se le ymbiaron vendiese allá (ASIL, Documentación en papel, I-e/74-1,b, f.113r). El mismo Toro, vicario en el momento de la visita, poseía una interesante colección de libros, patrimonio que se relaciona en la documentación de su almoneda. (ASIL, Documentación en papel, F-b/ 44, 39).

${ }^{38}$ Añadido al margen. 
impreso $^{39}$ - es el siguiente: vn breuiario de quarto de pliego del reço nuevo por donde se haze el offiçio ${ }^{40}$ y un ejemplar, pues, de pequeño formato y adecuado ya a la reforma litúrgica tridentina. Los restantes volúmenes inventariados son, parece, cantorales propiamente dichos que suponemos, por analogía con otras bibliotecas corales coetáneas, manuscritos $^{41}$. Las observaciones del secretario a propósito de las características externas de estos ejemplares, que en otros centros sobresalen por su especial prestancia, son pocas y escuetas, se limitan a imprecisas afirmaciones sobre el tamaño: 'grande', 'mediano', 'pequeño'. En sólo cuatro casos se especifica si el contenido de los volúmenes se ajusta o no a las prescripciones tridentinas. Se habla de Dos libros nuebos, vn psalterio biejo, de lo antiguo y de tres libros que contienen el offiçio vespertino de todo el año, avnque le falta mucho según el reço nuevo.

Respecto a estos últimos, ordena el prior isidoriano mirasen lo que faltaua y se apuntase conforme al reço nuevo, indicación que parece sugerir la posibilidad de modificar, no de sustituir, los volúmenes afectados, incorporando las novedades y suprimiendo el texto obsoleto para prolongar en lo posible la vida útil de unos libros que resultaban especialmente costosos ${ }^{42}$.

En lo que se refiere al contenido, el texto emanado de la visita es más explícito. Además del salterio, cuentan los moradores de la Vega con tres libros destinados específicamente al Oficio Divino, que contienen el offiçio vespertino de todo el año.

También disponen de graduales o cantorales para el desarrollo de la Misa: de tempore, de santos (propio y común): Dos libros nuebos grandes que contienen el vno las missas proprias de las fiestas y el otro las del commún", otro que contiene el offiçio de las missas de todo el año y un volumen con las piezas del ordinarium missae, tanto las principales -el Kyrie, el Sanctus y el Agnus Dei- como el Gloria y

${ }^{39}$ Nos basamos en las adquisiciones de libros en otros centros eclesiásticos, como el monasterio cisterciense de Santa María de Valdediós, en los cuales los breviarios propiamente dichos son siempre impresos (A. SUÁREZ GONZÁLEZ, Adquisiciones de libros en Valdediós entre 1581 y 1789: Actas del II Congreso de Bibliografía asturiana, vol. III, Oviedo 1999, pp.1047-1077).

${ }^{40}$ ASIL, Documentación en papel, L/102-1, f.[22]r.

${ }^{41}$ Cf. A. SUÁREZ GONZÁLEZ, Los libros de coro de Valdediós. I. Historia, Valdediós 2001 e ID., Los libros de coro de Valdediós. II. Catálogo, Valdediós 2001 (en adelante, Valdediós I y Valdediós II respectivamente).

${ }^{42} \mathrm{La}$ constante remodelación de cantorales, hasta llegar a convertirlos en libros de estructura muy compleja, es una costumbre muy frecuente, cf. Valdediós I y Valdediós II. 
Ana Suárez

el Credo. Yten: vn "libro de quiriis (sic), glorias, credos, sanctus y agnus" que tiene algunas missas proprias y comunes.

Completan la biblioteca coral un libro de lamentaçiones y offiçio de la Semana Sancta y tres pasioneros.

\subsection{Ejemplares de la librería.}

Es la denominada librería la biblioteca convencional de Nuestra Señora de la Vega, la que reúne los libros que pueden ser objeto de lectura privada y la que mejor refleja los intereses y las necesidades intelectuales de sus moradores.

La relación que el secretario lleva a cabo consta de cuarenta y nueve entradas que comprenden aproximadamente ochenta volúmenes, ejemplares que se hallan en la librería cuando el prior isidoriano realiza su inspección. Diez asientos más explicitan los libros que se creían 'perdidos'. El inventario parece no seguir un orden atendiendo a temas o a autores, tal vez se enumeran los volúmenes tomando como base su ubicación.

Los asientos bibliográficos son sumamente escuetos, demasiado. Interesa determinar cuál es el contenido, del modo más sucinto posible. Unas veces sólo se transcribe la totalidad o parte del título:

vna Secunda secundae [6]

vn libro intitulado Index operum Chrisostomi [16]

otro libro intitulado Flores Auicenae [25]

Otras se cita el autor:

Vn sant Ambrosio [2]

las obras de sant Bernardo [7]

las obras de sant Ylario [8]

las obras de sant Anselmo [9]

las obras de sant Buenabentura [13]

las obras de Joan Gerson [15]

vn Séneca [38]

vn Marçial [39]

Algunas entradas ofrecen ambos datos:

de Soto, sobre el quarto de las sentençias, en dos tomos buenos y

De iustitia et iure en otro y otro Sobre la Epistola ad Romanos [11].

Caietano, Sobre los euangelios [12]

Gabriel, sobre todo el maestro de las sentençias, y otro del mesmo sobre el terçero de las sentencias [14]

dos libros biexos de Erasmo, vno de sus epístolas y otro De conscribendis epistolis [17]

ay otro libro de Castro, Aduersus haereses [20] 
El patrimonio bibliográfico comunitario de Sta. $M^{a}$ de la Vega

ay Euthimio Super psalmos y Sobre los quatro euangelios [21] otro libro del maestro Frías De modo audiendi confessiones [23] vnas Relectiones del maestro fray Francisco de Victoria [24] vn maestro de las sentençias, Super epistolas D. Pauli [33] bitual:

$\mathrm{O}$ se resuelven reproduciendo una denominación abreviada ha-

vna glossa ordinaria [1]

vna Summa Angelica [18]

No interesa el aspecto externo de los libros, aunque sí suele especificarse en cuántos 'tomos' o 'cuerpos' se distribuye una determinada obra. Las alusiones al formato -que se limitan a precisar si se trata de volúmenes 'pequeños', 'medianos' o 'grandes'- son raras ${ }^{43}$. Además, sólo excepcionalmente se hace referencia a la encuadernación -con apuntes como los siguientes:

enquadernada en beçerro [1]

enquadernado en tabla [2]

enquadernadas en pergamino [3]

bien enquadernado [12]

bien enquadernadas [13]-

o a la calidad material de los ejemplares, empleando los adjetivos $r a-$ zonable $^{44}$ o bueno ${ }^{45}$.

Tampoco se mencionan años, lugares de edición y nombres de editores $^{46}$. La referencia a la edad del libro se limita a las observaciones 'antiguo' o 'muy antiguo, ${ }^{47}$.

No nos sorprende la simplicidad en el formulario de las entradas si tenemos en cuenta a los destinatarios de esta relación, aquéllos a quienes se pretende informar. Son el abad y el cabildo isidorianos, sin duda suficientemente familiarizados con las obras citadas como para reconocerlas bajo títulos abreviados o con la sola mención del apellido del autor. Hoy, fuera del contexto en el que dichos textos gozaron del favor de los lectores y se manejaron con frecuencia, la interpretación de algunos apuntes plantea dificultades. Cuando sólo se menciona el nombre de un autor ise trata de una obra debida a dicho personaje o nos hallamos ante el texto de un comentarista? El adjetivo biejo se presta a la ambiguiedad ¿alude al estado de conservación o se refiera a

${ }^{43}$ Remitimos a las entradas 10, 22 y 36 del Apéndice III.

${ }^{44}$ Véase la entrada 4.

${ }^{45}$ Remitimos a las entradas 4, 10, 11 y 12 .

${ }^{46}$ Razón por la cual hemos desestimado realizar propuestas sobre la identificación concreta de los ejemplares citados, a diferencia de lo que hemos llevado a cabo en otros trabajos (cf. A. SUÁREZ GONZÁLEZ, Adquisiciones, pp.1047-1077).

${ }^{47}$ En las entradas 10, 36, 46 y 48. 
Ana Suárez

la data $?^{48}$. Contenidos especificados con epígrafes demasiado genéricos o comunes -obras- impiden una identificación precisa del texto en unos casos y del autor en otros. Llama la atención, asimismo, la peculiar manera de transcribir nombres ${ }^{49}$, títulos e initia de las obras. A veces se confunde el nombre del autor, Joan Stapulensis, Super Ethica Aristotelis et alia $[35]^{50}$, y se advierten errores que podrían deberse a una copia del secretario bajo dictado del prior ${ }^{51}$.

En fin, entradas como las que siguen, relativas, parece, a obras gramaticales, nos resultan demasiado imprecisas: dos artes griegas [29] u otro intitulado Antonio [45].

A pesar de estos obstáculos, sí podemos formarnos una idea bastante precisa de la biblioteca que nos ocupa, biblioteca a la que cabe aplicar cuatro adjetivos: impresa, latina, teológica y actualizada ${ }^{52}$.

Hablamos de librería impresa pues, parece, la única excepción la constituye un breviario de mano, antiguo [36],

Es el que nos ocupa un conjunto bibliográfico que se expresa en latín, con escasísima presencia de textos en castellano como la ' $\mathrm{Co}$ rónica' de los frailes augustinos, en romançe [42].

$\mathrm{Y}$ es una biblioteca esencialmente teológica en los contenidos y actualizada, si tenemos en cuenta la fecha de redacción de muchas de las obras presentes en ella.

Para facilitar el acceso a esta librería y hacernos mejor idea de los saberes representados, plantearemos una clasificación de las obras referidas en el inventario atendiendo a sus temas.

${ }^{48}$ Véanse las entradas 5, 6, 17, 48 y 56.

${ }^{49}$ Sirva de ejemplo la entrada 55, relativa a un libro desaparecido: la obra de Gaspar Grajar In Micheam prophetam commentaria que se atribuye a un tal "Grajal".

${ }^{50}$ Creemos que el secretario fundió los nombres del comentarista de Aristóteles Jacobus Faber Stapulensis con el del traductor Iohannes Argyropoulo. Al respecto de esta obra "el trabajo de Juan Argiropulo" (...) "va a ser la clave en la renovación del aristotelismo" (C. FLÓREZ MIGUEL, La cultura filosófica en Europa de 1450 a 1550: Congreso Internacional sobre Humanismo y Renacimiento, vol. II, León 1998, p.342). Otro caso análogo podría ser el de la entrada 44: "libro Joannis Lyrinensis", registro en el que tal vez se mezclan dos figuras: san Vicente de Lérins y el comentarista de su obra Pro catholicae fidei antiquitate et veritate Iohannes Costerius.

${ }^{51}$ Es el caso del curioso asiento "De sacro altaris mysterio"[26] (se tachó la palabra mysterio) que sólo la apostilla "llámase Gaufredus" permitiría atribuir a la Summa super titulos Decretalium debida a Gaufredus de Trano.

${ }^{52}$ Tan actualizada que, incluso, entre las obras desaparecidas se refiere una "oración" de Pedro de Herrera (entrada 59) autor aún joven en 1577 y profesor de Teología en la Universidad salmantina (cf. G. FRAILE, Herrera, Pedro de: Diccionario de Historia Eclesiástica de España, vol. 2, Madrid 1972, p.1089). 
Comenzaremos por el apartado estrictamente litúrgico, que, si bien no constituye numéricamente el sector más relevante en la librería, es interesante porque completa los conjuntos bibliográficos que se hallan en el coro y en la sacristía de la casa. Dos parecen ser las razones por las que se encuentran depositados en la librería ejemplares concebidos para el desarrollo del Oficio Divino y la Misa: su edad -y, tal vez, asociado a ella, un deficiente estado de conservación- y su inutilidad para la función litúrgica, por recoger textos que no se ajustan a la reforma tridentina. Nos referimos a seis volúmenes, cinco de ellos breviarios tres breuiarios grandes, de los romanos, antiguos y otros dos pequeños del mesmo reçado y otro de mano, antiguo [36] y un missal biejo, de lo antiguo [48]

No podían faltar en la librería de Nuestra Señora de la Vega ejemplares bíblicos. Una de las entradas del inventario refiere la existencia de çinco blibias (sic) [10] otra consigna la presencia de la glossa ordinaria [1] y, además, se advierte la desaparición de un Testamentum nouиm [51]

Facilitan el acceso a la Escritura obras auxiliares, como concordancias y enquiridiones ${ }^{53}$.

En relación con la Biblia, puesto que uno de sus fines esenciales es la predicación de la Sagrada Escritura, se halla la Teología, sin lugar a dudas la materia dominante en la librería tanto por el número de volúmenes como por la actualidad de las obras.

La relación de textos muestra la riqueza de un fondo en el cual están presentes tanto los textos de los primeros Padres de la Iglesia como los tratados contemporáneos más recientes. Disponen los moradores de La Vega de patrística antigua -griega y latina- directamente o transmitida a través de comentaristas, si bien las escuetas entradas del inventario no permiten diferenciar en todos los casos si nos hallamos ante unos u otros textos. En lo que se refiere a los padres latinos aparecen citados varios ejemplares con obras de Jerónimo ${ }^{54}$, Ambrosio de Milán ${ }^{55}$, Hilario de Poitiers ${ }^{56}$ y Agustín de Hipona ${ }^{57}$ y se registra entre los libros desaparecidos un volumen con textos de Gregorio Magno ${ }^{58}$. Por lo que respecta a la patrística griega, figuran en el inventario tex-

\footnotetext{
${ }^{53}$ Entradas 34 y 41.

${ }^{54}$ Entrada 32.

${ }^{55}$ Entradas 2, 3.

${ }^{56}$ Entrada 8.

${ }_{58}^{57}$ Entrada 49.

${ }^{58}$ Entrada 52.
} 
Ana Suárez

tos de Juan Crisóstomo ${ }^{59}$, Eutimio Zigabono ${ }^{60}$, Juan Clímaco ${ }^{61}$ y Theophylactus Bulgarus ${ }^{62}$.

Entre los tratadistas medievales, se mencionan figuras como san Anselmo de Canterbury ${ }^{63}$, san Bernardo ${ }^{64}$ y san Buenaventura ${ }^{65}$ y, por supuesto, el maestro de las sentencias. De Pedro Lombardo encontramos el Comentario a las epístolas paulinas ${ }^{66}$ y se refieren en el inventario, además, diversos comentarios a sus obras como los debidos a Gabriel Biel ${ }^{67}$ y el dominico Domingo de Soto, autor en el que nos detendremos más adelante. La escuela teológica parisina no sólo halla representada con Pedro Lombardo, también se citan textos de Jean Charlier de Gerson ${ }^{68}$.

Sobresale la presencia de Tomás de Aquino y de sus seguidores. Del padre de la escolástica cuenta la comunidad de canónigos con ejemplares tanto de la Summa Sacrae Theologiae ${ }^{69}$ completa como, específicamente, de su Secunda Secunde ${ }^{70}$. Señalábamos anteriormente que en los que se refiere a contenidos la librería que nos ocupa está actualizada, por ello tiene también cabida la escolástica moderna. Del cardenal Tomás de Vio -Caietano- vemos los Comentarios a los evangelios $^{71}$ y de Francisco de Vitoria las Relectiones theologicae ${ }^{72}$.

Otro tomista se encuentra muy presente, el ya citado teólogo Domingo de Soto, que fue catedrático en la Universidad de Salamanca. Custodia la librería sus In quartum sententiarum commentarii, De

${ }^{59}$ La entrada 16 es confusa y podría aludir tanto a las obras propiamente dichas como a un comentario. En la entrada 56 se alude a unas homilías del mismo autor desaperecidas de la librería.

${ }^{60}$ Entrada 21.

${ }^{61}$ Entradas 27 y 51. En la primera de las citadas la trascripción del título nos lleva a pensar que se trata de la traducción realizada por Ambrosio Traversari. El segundo de los registros indica que desapareció de la biblioteca otra obra de Juan Escolástico.

${ }^{62}$ Entrada 31.

${ }^{63}$ Entrada 9.

${ }^{64}$ Entrada 7.

${ }^{65}$ Entrada 13.

${ }^{66}$ Entrada 33.

${ }^{67}$ Véase la entrada 14. Se refiere a Super librum sententiarum y Super tertium sententiarum.

${ }^{68}$ Véase la entrada 15. El genérico obras probablemente alude a una recopilación de tratados bajo el título Opera.

${ }^{69}$ Entradas 4 y 5.

${ }^{70}$ Entrada 6.

${ }^{71}$ Entrada 12.

${ }^{72}$ Entrada 24. 
iustitia et iure libri decem e In epistolam Divi Pauli ad Romanos ${ }^{73} \mathrm{y}$ contuvo con anterioridad también su De natura et gratia, libro desaparecido en el momento de la visita ${ }^{74}$.

Al también maestro teólogo de la Universidad de Salamanca, el franciscano Alfonso de Castro, debemos el tratado Adversus omnes hereses $^{75} \mathrm{y}$, en análoga línea temática, cabe citar la obra de otro tratadista contemporáneo: Joannes Eck ${ }^{76}$.

Llama nuestra atención una de las entradas relativa a obras que se consideran de Erasmo de Rotterdam, pero cuya redacción, sin embargo, parece conducirnos al humanista valenciano Juan Luis Vives ${ }^{77}$.

Convendría hacer un apartado específico con ciertos tratados de Teología moral, que no sólo resultan útiles para la formación personal sino que también muestran la vertiente pastoral de la comunidad de Nuestra Señora de la Vega. Se pueden encuadrar en este apartado la Summa Angelica de casibus conscientie de Fr. Ángel de Clavasio ${ }^{78}$, el De arte et modo audiendi confessiones de Martín de Frías, profesor de la Universidad salmantina ${ }^{79}$.

En esta vertiente pastoral cabe insertar compilaciones de sermones como las debidas a Pedro de Palude ${ }^{80}$ y, para concluir con las obras de de carácter religioso-eclesiástico, debemos mencionar una mínima presencia hagiográfica ${ }^{\mathbf{8 1}}$.

Pese a que, como demuestran las fuentes isidorianas, algunos canónigos cursaban en Salamanca estudios de Derecho canónico, esta disciplina apenas se ve representada. Sólo se alude -de manera confusa- a una obra de Gaufredus de Trano ${ }^{82}$ y se constata la desaparición de unas Decretales ${ }^{83}$.

La biblioteca se completa con clásicos latinos ${ }^{84}$ (Terencio $^{85}$, Séneca $^{86}$ y Marcial $^{87}$ ), filosofía (Aristóteles, Pedro Hispano ${ }^{88}$ ), historia

\footnotetext{
${ }^{73}$ Véase la entrada 11

${ }^{74}$ Remitimos a la entrada 53, entrada en la que también se cita el liber octavus
} del De natura et iure: "De iuramento et adiuratione".

${ }^{75}$ Entrada 20.

${ }^{76}$ Entrada 22.

${ }^{77}$ Entrada 17.

${ }^{78}$ Entrada 18.

${ }^{79}$ Entrada 23.

${ }^{80}$ Entrada 30.

${ }^{81}$ Entrada 40.

${ }^{82}$ Entrada 26.

${ }^{83}$ Entrada 56.

${ }^{84}$ Contuvo asimismo un Ars amandi de Ovidio que se da por desaparecida en el momento de la visita (véase la entrada 57).

${ }^{85}$ Entrada 37. 
Ana Suárez.

(una crónica $^{89}$, el texto atribuido en el título a Antonio de Nebrija relativo al reinado de los reyes Católicos ${ }^{90}$ ) y medicina: una recopilación de opúsculos de Avicena ${ }^{91}$ y un libro intitulado Información para curar la peste $e^{92}$.

\section{3.- Los usuarios en los libros, los usuarios $y$ los libros.}

En el inicio de esta aproximación presentábamos a los seis usuarios de los libros cuando visita La Vega Juan de Villafañe. Pero ¿qué nos dice de ellos el patrimonio bibliográfico comunitario de la casa? La presencia de un fondo litúrgico coral confirma que se trata de regulares, la composición de la biblioteca refleja una comunidad de estudiantes, pero no de estudiantes cualesquiera. No tienen cabida en ella obras de entretenimiento y son pocos los clásicos aptos para un aprendizaje básico de la lengua latina ${ }^{93}$. Es un conjunto apropiado para aspirantes a títulos superiores, de carácter universitario, condición parece, de cinco de los seis moradores de La Vega ${ }^{94}$.

Pero podemos precisar aún más. Abriendo la librería es evidente que sus usuarios cursan, mayoritariamente al menos, Teología, y que "oyen esta facultad" en las escuelas de Salamanca.

Así, custodia la biblioteca los manuales imprescindibles en las cátedras de Teología de la Universidad salmantina, donde se leía a

\footnotetext{
${ }^{86}$ Entrada 38.

${ }^{87}$ Entrada 39.

${ }^{88}$ Entrada 35 y 46. Respecto a la entrada 35, remitimos a lo dicho en nota 50.

${ }^{89}$ Entrada 42. La redacción de la noticia es confusa.

${ }^{90}$ Entrada 28. Para especificar la obra el secretario toma parte del título Rerum a Fernando et Elisabe Hispaniarum foelicissimis regibus gestarum decades duas. También correspondería a Nebrija la entrada 45.

91 Entrada 25.

92 Entrada 43.

${ }^{93}$ A Nuestra Señora de la Vega se envían estudiantes para cursar estudios supe-
} riores, no para una enseñanza elemental o básica a la que se podía dar respuesta satisfactoria en el recinto isidoriano. Así, se acuerda que no vaya a La Vega ynfante ninguno a estudiar granmática, que era infamia de esta casa y de la otra (en 1563, noviembre, 6; ASIL, Documentación en papel, I-e/74-1,a, ff.139v-140r) y que los moradores acudan a aprender "otra facultad y no gramática" (en 1577, agosto, 23; ASIL, Documentación en papel, I-e/74-1,b, f.1116v). Por ello, como advertíamos a propósito de Diego de Vega, era excepcional el envío a Salamanca de infantes para aprender la lengua latina.

${ }^{94}$ Según la relación de matriculaciones que recoge C. I. RAMÍREZ GONZÁLEZ, Las órdenes religiosas en la Edad Moderna: Historia de la Universidad de Salamanca. I. Trayectoria histórica e instituciones vinculadas, Salamanca 2002, p.588, fueron cinco los alumnos matriculados procedentes de Nuestra Señora de la Vega en el curso 1576-1577. 
Pedro Lombardo en los Libros de las Sentencias, a lo largo de los cuatro cursos de estudio pasivo, hasta su empleo simultáneo junto con la Suma Teológica de Santo Tomás ${ }^{95}$, puesto que el tomismo constituía el eje del programa docente. Además, basta un vistazo a la relación de obras para advertir el peso de los textos tomistas y un repaso a la nómina de autores para notar la importante presencia de maestros salmantinos (Domingo de Soto, Alfonso de Castro, Martín de Frías).

Decíamos al describir la composición de la librería que carecemos de datos sobre lugares y responsables de impresión. No descartamos el origen de una buena parte de los libros en la misma villa del Tormes, importante centro editorial en la época que nos ocupa ${ }^{96}$.

Tal vez, la escasa presencia del Derecho canónico indique que, en el momento de la visita, no se hallaban en Nuestra Señora de la Vega futuros juristas, pese a que, a lo largo del siglo XVI, la Universidad de Salamanca sobresalió por los estudios de Derechoo ${ }^{97}$ y sabemos que también canónigos isidorianos que se decantaron por esta especialidad $^{98}$.

${ }^{95}$ M. ANDRÉS MARTÍN, La facultad de Teología: La Universidad de Salamanca. II. Atmósfera intelectual y perspectivas de investigación, Salamanca 1990, p.64. Según los estatutos de la Universidad de Salamanca de 1561, el catedrático de Teología debía "leer" la Secunda Secundae de la Summa Theologica tomista distribuida en los años cuarto a sexto de la titulación (Ibídem, p.65).

${ }^{96}$ Cf. J. A. SÁNCHEZ PASO, La Universidad de Salamanca en la impresión y edición de libros: El libro antiguo español. Actas del II Congreso Internacional, Salamanca 1992, pp.449-456 y A. ROJO VEGA, Comercio e industria del libro en el noroeste peninsular. Siglo XVI: El libro antiguo español. Actas del II Congreso Internacional, Salamanca 1992, p.425: "El área noroeste tiene dos cabezas que rigen comercio e industria sin molestarse entre sí, sobre todo a partir de la tercera década del siglo: Salamanca es el centro industrial del libro por excelencia y Medina del Campo centro del gran comercio de importación".

97 ...nuestra Universidad fue desde el principio eminentemente jurídica (V. BELTRÁN DE HEREDIA, Los orígenes de la Universidad de Salamanca, Salamanca 1953, p.69). Coinciden con esta observación M. PESET y E. GONZÁLEZ GONZÁLEZ, Las facultades de leyes y cánones: La Universidad de Salamanca. II. Atmósfera intelectual y perspectivas de investigación, Salamanca 1990, p.10. La Salamanca del siglo XVI se presenta prioritariamente como una Universidad de juristas, señaladamente canonistas, que cuenta con una Facultad de Teología de cierta importancia (L. E. RODRÍGUEZ-SAN PEDRO BEZARES, Universidad de la Monarquía Católica, 1555-1700: Historia de la Universidad de Salamanca. I. Trayectoria histórica e instituciones vinculadas, Salamanca 2002, p.107).

98 Teniendo en cuenta los datos recogidos en J. ALEJO MONTES, La Universidad, p.296, a través de los registros de matrícula salmantinos, en el curso académico 1575-1576 se habían matriculado en la Universidad de Salamanca siete estudiantes de $\mathrm{N}^{\mathrm{a}}$. Sra de la Vega: dos en Cánones, 4 en Teología y uno en facultad sin especificar. 
Ana Suárez

Lo mismo cabe decir de otras 'facultades' como las Artes o Filosofía - 'facultad' que el cabildo isidoriano determinó que había de oír Diego de Vega- y la Medicina. A estas disciplinas remiten muy pocas obras, eso sí, básicas, como las Summulae logicales de Pedro Hispano ${ }^{99}$ o el compendio de textos de Avicena ${ }^{100}$.

¿Dónde y cómo accedían a los ejemplares bibliográficos los moradores de La Vega? Por lo que se refiere a los volúmenes litúrgicos, los libros depositados en la sacristía se utilizarían en la iglesia, para lo cual dispone la comunidad de tres façistoles para decir epístolas y evangelios y çinco atriles para decir missa, para los missales ${ }^{101}$, todos ellos de madera.

Los ejemplares de coro se emplean in situ. La documentación que genera la visita es muy explícita en la descripción de este espacio y del mobiliario relacionado con la custodia y la utilización de los libros. Consta la existencia en el recinto coral de vn façistol pequeño sobre el que se deposita el breviario que sirve de guía al desarrollo del oficio, y, destinado a los cantorales propiamente dichos, un façistol grande, redondo, con tres lazenas en el pie ${ }^{102}$.

Este mueble, de gran envergadura y capacidad, servía, pues, a dos funciones: garantizaba una adecuada guarda de los libros en el armario de su parte inferior y permitía el acceso a su contenido mediante la plataforma giratoria en la que seguramente podían disponerse la totalidad de los ejemplares necesarios en el curso de un determinado oficio.

Son escasas y confusas las noticias sobre la ubicación y características físicas de la librería. Se menciona la existencia de llaves, por lo que deducimos que se trataba de un armario cerrado, y se alude a la responsabilidad del tesorero -que ejercería en cierta medida como bibliotecario- por lo que el armario custodio de los libros se encontraría seguro, en el mismo recinto que el tesoro.

\footnotetext{
${ }^{99}$ Entrada 46. En la Facultad de Artes y Filosofía de la Universidad de Alcalá de Henares "el regente de súmulas" estaba obligado a leer esta obra "durante dos horas por la mañana y una por la tarde, con sus correspondientes cuestiones y reparaciones" (A. ALVAR EZQUERRA, Un modelo de organización docente: la Universidad de Alcalá de Henares a principios del siglo XVI: Congreso Internacional sobre $\mathrm{Hu}-$ manismo y Renacimiento, vol. I, León 1998, p.110).

100 Ver entrada 25. Sobre la importancia de la obra de Avicena en la facultad de Medicina de Alcalá de Henares, cf. A. ALVAR EZQUERRA, Un modelo, p.113.

${ }^{101}$ Entre las piezas de madera se citan estos "tres façistoles" y "çinco atriles" (ASIL, Documentación en papel, L/102-1, f.[20v].

${ }^{102}$ ASIL, Documentación en papel, L/102-1, f.[22r].
} 
La lectura de los ejemplares de la librería se lleva a cabo en privado, en los aposentos, aunque sólo se refiere en detalle el mobiliario del destinado al prior, en el que hallamos vn estudio con vna ventana (...) vn scriptorio de nogal ques del conuento y vna mesa de nogal grande con vn caxon de pino debaxo de ella ${ }^{103}$.

¿Se valoraba en Santa María de la Vega el patrimonio bibliográfico? Sí. De la importancia concedida a los libros es buena muestra el castigo aplicado a los miembros de la comunidad cuando se constata la desaparición de diez ejemplares de la librería:

Visto por el señor prior que faltaban los libros supra scriptos mandó que todos los que vbiesen tenido las llaues de la dicha librería o si alguno tenía alguno destos dichos libros en su poder o le aya dado a alguna persona lo manifieste dentro de veinte e quatro horas so pena de excommunión maior latae sententiae.

$$
* * *
$$

Nos hemos acercado al conjunto bibliográfico comunitario de Nuestra Señora de la Vega en un momento -el último cuarto del siglo XVI- especialmente interesante para la historia del libro en general y del libro eclesiástico en particular. Es un periodo híbrido en técnicas de confección y un tiempo de cambios y de renovación en lo que afecta a los contenidos. Hallamos en la filial de Salamanca manuscritos e impresos, con un dominio claro de los primeros, pero con una significativa presencia de los segundos en el ámbito coral.

¿Qué valoración nos merece este conjunto bibliográfico?

Santa María de la Vega posee una biblioteca litúrgica muy básica y, probablemente, teniendo en cuenta las escuetas referencias a su aspecto, dotada de ejemplares formalmente sencillos. Encontramos ejemplares de 'rezo nuevo' junto a libros de 'rezo viejo', expresiones que indican si los volúmenes se ajustan o no a las prescripciones del Concilio de Trento y, por ello, si pueden o no ser utilizados. Teniendo en cuenta que el nuevo breviario y el nuevo misal romano no se publicaron hasta 1568 y 1570 respectivamente ${ }^{104}$, es evidente que los canónigos isidorianos estaban 'al día', preocupados por la actualización de su biblioteca litúrgica. Así pues, en la filial salmantina, al igual que en otros centros eclesiásticos coetáneos, se impone una costosa renova-

${ }^{103}$ ASIL, Documentación en papel, L/102-1.

${ }^{104}$ Cf. B. LLORCA y R. GARCÍA VILLOSLADA, Historia de la Iglesia católica. III. Edad Nueva. La Iglesia en la época del Renacimiento y de la Reforma católica, Madrid 1960, p.857. 
Ana Suárez.

ción de los ejemplares litúrgicos puesto que, en corto espacio de tiempo, se han vuelto inservibles la mayoría de los concebidos para el adecuado desarrollo del Oficio divino y de la misa.

Nos sorprende, asimismo, el reducido número de volúmenes de la librería, que podemos calificar sin reservas de teológica, tal vez porque la visitamos cuando acaba de ser expurgada y desprovista de obras consideradas en el momento no ortodoxas o por el peso de las bibliotecas privadas de los miembros de la comunidad.

En todo caso, valorando en su conjunto el fondo librario comunitario de la Vega -ejemplares de sacristía, de coro, de librería- llegamos a la conclusión de que la casa salmantina dispone sólo de los textos imprescindibles; su patrimonio bibliográfico es, pues, el estrictamente "justo y necesario" para satisfacer sus obligaciones litúrgicas y dar respuesta a sus preocupaciones intelectuales.

\section{APÉNDICE}

Visita a la Vega de Salamanca en 1577

ASIL, Documentación en papel, L/102-1, ff. [20v] y [22]r-[24r].

\section{[Relación de libros]}

\section{I}

f. $[20] \mathrm{v}$.

[Sacristía]

"Missales

Tres missales del reço nuebo, el vno grande, los otros dos pequeños (el vno más que el otro).

Yten: diez y nuebe missales biejos del reço antiguo que no siruen.

Mandó el dicho señor prior se comprasen otros tres missales de los nuebos para que aya en todos seis" <mandato: no III, sino quatro $>^{105}$.

II

f. [22r]

[Choro]

"Yten, vn façistol pequeño con vn breuiario de quarto de pliego del reço nuevo por donde se haze el offiçio.

${ }^{105}$ Añadido al margen. 
Yten, vn façistol grande redondo con tres lazenas en el pie. Tiene los libros siguientes:

Dos libros nuebos grandes que contienen el vno las missas proprias de las fiestas y el otro las del commún.

Yten: vn psalterio biejo, de lo antiguo, mediano.

Yten: vn "libro de quiriis (sic), glorias, credos, sanctus y agnus" que tiene algunas missas proprias y comunes.

Yten: otro que contiene el offiçio de las missas de todo el año.

Yten: tres libros, los dos grandes y el otro pequeño, que contienen el offiçio vespertino de todo el año, avnque le falta mucho según el reço nuebo.

(en lo qual mandó mirasen lo que faltaua y se apuntase conforme al reço nuebo) //

f. [22]v

Yten: vn libro de lamentaçiones y offiçio de la Semana Sancta.

(...)

Yten tres pasioneros.

III

f. [23]r

[Librería]

"Yten: visitó el dicho señor prior la librería de la dicha casa de Nuestra Señora de la Vega, en la qual se allaron los libros siguientes:

[1] Primeramente, vna "glossa ordinaria", enquadernada en beçerro en seis cuerpos.

[2] Yten: "Vn sant Ambrosio", en dos cuerpos, enquadernado en tabla. Los quales y la glossa se compraron de la dézima que cabía a los illustres señores prior y conbento de Santo Isidro de León, de la qual parte hizieron merced a esta casa para comprar libros por ser casa de studio.

[3] Yten: otras "obras" de sant Ambrosio enquadernadas en pergamino.

[4] Yten: vnas "partes" de sancto Thomás, raçonables, a las quales falta la primera parte. jas.

[5] Yten: ay dos primeras "partes" de sancto Thomás, muy biepor sí.

[6] Yten: vna "Secunda secundae" bieja, con vnos "quodlibetos"

[7] Yten: las "obras" de sant Bernardo en vn cuerpo. 
Ana Suárez

[8] Yten: las "obras" de sant Ylario en vn cuerpo.

[9] Yten: las "obras" de sant Anselmo en otro.

[10] Yten: çinco "blibias" (sic), las dos grandes y buenas y las tres medianas, de las antiguas.

[11] Yten: ay estas ${ }^{106}$ obras de Soto, "sobre el quarto de las sentençias", en dos tomos buenos y "De iustitia et iure" en otro y otro "Sobre la Epistola ad Romanos".

[12] Yten: Caietano, "Sobre los euangelios", en vn cuerpo bien enquadernado y bueno.

[13] Yten, las "obras" de sant Buenabentura en dos tomos, bien enquadernadas.

[14] Yten: Gabriel, sobre todo el maestro de las sentençias, y otro del mesmo sobre el terçero de las sentencias.

[15] Yten: las "obras" de Joan Gerson en quatro tomos todas.

[16] Yten: ay vn libro intitulado "Index operum Chrisostomi".

[17] Yten: dos libros biexos de Erasmo, vno de sus epístolas y otro "De conscribendis epistolis".

[18] Yten: vna "Summa Angelica".

[19] Yten: otro libro intitulado Joannes Eunomius, "Super epistolas Pauli".

[20] Yten: ay otro libro de Castro, "Aduersus haereses".

[21] Yten: ay Euthimio "Super psalmos" y "Sobre los quatro euangelios" en vn cuerpo.

[22] Yten: Joannes Echius en quatro tomos pequeños.

[23] Yten: otro libro del maestro Frías "De modo audiendi confessiones".

[24] Yten: vnas "Relectiones" del maestro fray Francisco de Victoria.

[f.23v]

[25] Yten: otro libro intitulado "Flores Auicenae".

[26] Yten: otro intitulado "De sacro altaris mysterio (tachado)", llámase Gaufredus.

[27] Yten: ay otro intitulado "Climax, Joannis Scholastici".

[28] Yten: otro intitulado "Decadae duae, Antonii Nebrisensis".

[29] Yten: dos artes griegas.

[30] Yten: vnos sermones de Pedro de Palude.

[31] Yten: el primer tomo de las "obras" de Theophilato en el qual está el otro tomo.

[32] Yten: vnas "epístolas" viexas de sant Hieronymo.

${ }^{106}$ Enmendado, escrito inicialmente "obras". 

Pauli”.

[33] Yten: vn maestro de las sentençias, "Super epistolas D.

[34] Yten: "Similitudines Bibliae".

[35] Yten: Joan Stapulensis, "Super Ethica Aristotelis et alia.

[36] Yten: tres breuiarios grandes, de los romanos, antiguos y otros dos pequeños del mesmo reçado y otro de mano, antiguo.

[37] Yten: vn Terençio comentado.

[38] Yten: vn Séneca.

[39] Yten: vn Marçial.

[40] Yten: "Vitas quorundam sanctorum".

[41] Yten: "Enchiridio psalmorum".

[42] Yten: Vna "Corónica" de los frailes augustinos, en romançe.

[43] Yten: otro libro intitulado "Información para curar la peste".

[44] Yten: otro libro Joannis Lyrinensis.

[45] Yten: otro intitulado Antonio.

[46] Yten: las "Summulas" de Petro Hispano, muy antiguas, con su "Logica".

[47] Yten: otro intitulado Joan Versiris Philosoph.

[48] Yten: vn missal biejo de lo antiguo.

[49] Yten: vn Augustino, "super euangelia, Joannem, canonicam et Apocalypssim.

Todos los quales dichos libros están en poder del canónigo Francisco Huerga en la tesorería, de todos lo quales él se dio por enterado y lo firmó de su nombre en siete de junio de 77

Francisco de la Huerga (rúbrica)

[añadido]

Digo yo, Lucas de Valderrama, thesorero, que al presente soy de Nuestra Señora de la Vega que me dí por entregado de todos los libros suprascriptos. Fecho en veinte de jullio de 1580 años

Excepto "Index operum Chrisostomi" y Séneca

[nota al margen]

$$
\text { Valderrama (rúbrica) }
$$

El Séneca paresçió después en poder de Pernía y se lo firmó.

[f.24r]

Los libros que faltan de la librería son los siguientes.

[50] Primeramente "Concordantiae Blibiae (sic)".

[51] Testamentum nouum.

[52] Sant Gregorio. 
Ana Suárez

[53] Soto, "De natura et gratia, et iuramento" en vn cuerpo.

[54] Sant Juan Clímaco.

[55] Grajal, "Super Micheam".

[56] Vnas "Decretales" biejas.

[57] Ouidio, "De arte amandi".

[58] "Homeliae Chrisostomi".

[59] Vna oraçión de Pedro Herrera.

Visto por el señor prior que faltaban los libros supra scriptos mandó que todos los que vbiesen tenido las llaues de la dicha librería o si alguno tenía alguno destos dichos libros en su poder o le aya dado a alguna persona lo manifieste dentro de veinte e quatro horas so pena de excommunión maior latae sententiae. Dada en Nuestra Señora de la Uega a postrero de junio de mill e quinientos y setenta y siete años.

Joan de Villafañe,

Prior de Santo Ysidro (rúbrica). 